\title{
Novel Analytical Method using Acquity QDa Mass Detector Coupled with LC-PDA for Impurity Profiling of Amlodipine Besylate and Olmesartan Medoxomil in Fixed Dose Tablets Formulation
}

\author{
Kondra Srinivasu $^{1,2^{*}}$, Dr. Bapuji A.T ${ }^{1}$, Dr. D Gowri Shankar ${ }^{2}$, Dr. Vijay Bharathi Dasari ${ }^{1}$, K.V.V. Satyanarayana ${ }^{1}$ \\ ${ }^{1}$ Aurobindo Pharma Limited, Bachupally, R.R District, Hyderabad-500090, India \\ ${ }^{2}$ College of Pharmaceutical Sciences, Andhra University, Visakhapatnam, Andhra Pradesh, India
}

\begin{abstract}
DOI: $10.36348 /$ SJMPS.2019.v05i10.008 $\quad$ | Received: 08.10.2019| Accepted: $18.10 .2019 \mid$ Published: 25.10 .2019
*Corresponding author: Kondra Srinivasu
\end{abstract}

\section{Abstract}

A novel impurity profiling technique for Amlodipine Besylate (ADB) and Olmesartan Medoxomil (OSM) in fixed dose combined tablets has been proposed by HPLC with Acquity Quadrupole Dalton analyser (QDa) mass detector coupled to photodiode array (PDA) detector. This online coupling technique has significant advantage over conventional HPLC techniques that mass and spectral characteristics can be evaluated simultaneously in a single run. The chromatographic separation was achieved on ACE C18 $(250 \times 4.6 \mathrm{~mm}$ id, $5 \mu$ particle size $)$ column with gradient mode using mobile phase composition of ammonium formate buffer, methanol and acetonitrile. Finalized flow rate was $1.0 \mathrm{~mL} / \mathrm{min}$ with quantification of $237 \mathrm{~nm}$. Moreover, identification of potential degradation product in stability condition samples was carried out by online coupling of PDA/QDa mass detection. This QDa mass spectrum reveals protonated molecular ion peak $[\mathrm{M}+\mathrm{H}]^{+}$at $\mathrm{m} / \mathrm{z} 875.5$ for degradation product. This major degradation product was further characterized using MS/MS ${ }^{2}$ integrated analytical tools. The method was validated systematically in terms of specificity, precision, linearity, accuracy, limit of detection (LOD), limit of quantification (LOQ) and robustness as per International conference on harmonization $(\mathrm{ICH})$ general guidelines. This proposed study can provide a creative idea and effective method for routine analysis of $\mathrm{ADB} / \mathrm{OSM}$ in tablet formulation in quality control department where impurity profiling as well as identification of unknown impurities can be evaluated simultaneously.

Keywords: Amlodipine Besylate, Olmesartan Medoxomil, QDa mass detector, impurity profiling, degradation products, validation.

Copyright @ 2019: This is an open-access article distributed under the terms of the Creative Commons Attribution license which permits unrestricted use, distribution, and reproduction in any medium for non-commercial use (NonCommercial, or CC-BY-NC) provided the original author and source are credited.

\section{INTRODUCTION}

Amlodipine Besylate (ADB) is chemically described as 3-ethyl-5-methyl ( \pm )-2-[(2-aminoethoxy) methyl]-4-(2-chlorophenyl)-1,4-dihydro-6-methyl3,5 pyridinedicarboxylate, monobenzene sulphonate. The molecular formula for ADB is $\mathrm{C}_{20} \mathrm{H}_{25} \mathrm{ClN}_{2} \mathrm{O}_{5} \cdot \mathrm{C}_{6} \mathrm{H}_{6} \mathrm{O}_{3} \mathrm{~S}$ having molecular weight of 567.1. It inhibits the transmembrane influx of calcium ions into vascular smooth muscle and cardiac muscle $[1,2]$. ADB is orally administered calcium channel blocker, widely used for the treatment of hypertension alone or in combination with other antihypertensive agents. Olmesartan Medoxomil (OSM) is a pro-drug, it is chemically described as 2, 3dihydroxy-2-butenyl 4(1-hydroxy-1-methylethyl)-2-propyl-1-[p-(o-1Htetrazol-5ylphenyl) benzyl] imidazole-5-carboxylate, cyclic 2, 3-carbonate, with molecular formula $\mathrm{C}_{29} \mathrm{H}_{30} \mathrm{~N}_{6} \mathrm{O}_{6}$ having molecular weight of 558.59. OSM is an angiotensin II receptor blocker (ARB) which selectively blocks the binding of angiotensin II to the AT1 receptor in vascular smooth muscle [3]. The combination of ADB and OSM tablets are used for treatment of hypertension and can be administered alone or with other antihypertensive agents. The decision of using fixed dose combination or monotherapy should be based on target blood pressure [4-7].

The literature survey reveals that, few analytical methods are available for the assay of ADB /OSM in tablets by spectrophotometric techniques [810], few articles by the HPLC methods for ADB /OSM tablets [11-13] and one method which describe the estimation of impurities alone which was published on combination product by using UPLC technique [14]. However, UPLC technique is very costly and complex instrument having very tedious procedure. Comprehensive literature survey revealed that none of 
pharmacopoeias or any journals published the methodology for simultaneous identification and quantification of $\mathrm{ADB} / \mathrm{OSM}$ combination dosage form or their degradants. The information regarding the stability of the product was also not available.

It is mandatory to identify, quantify and characterize the impurities, even in small amounts in the pharmaceutical products as per ICH guideline $(\mathrm{Q} 3 \mathrm{~B}$ (R2) 2006) [15], if they are present above the acceptance limit of $0.05 \%$ or $0.1 \%$ [16] with respect to the safety, efficacy and stability of pharmaceutical products. However identification of peaks in combination dosage forms is complex because of lower limits of detection, number of peaks, not able to monitor the possibility of co-elution, difficult to differentiate the peaks based on spectral characteristics by conventional HPLC/UPLC system. Therefore, the isolation of degradation products has been a general approach for identification and structural elucidation using ESI-TOF-MS or ESI-QDa-MS [17, 18].

Acquity QDa-mass detector is a promising new era technique for identification of high quality mass spectral data of analyte at ease thereby create potential scope of enhanced analytical confidence, minimize the risk of unexpected co-elutions, maximise productivity of each sample as it eliminates repetition of assay and tedious techniques compared to traditional mass instruments. Moreover it has advantage that as it can work in harmony with HPLC/UPLC with PDA/UV detector. Also it has significant synergic advantage of monitoring mass spectral characteristics and as well as optical spectral detection simultaneously in a single run. So it is felt essential to develop simple, cost effective and robust process to interpret, visualize and compare the most complex data in a single stability indicating HPLC method with online coupling QDa mass detector working in synergy with PDA detector.

The manuscript aims to develop new stability indicating HPLC method for simultaneous identification and quantification of related substances of $\mathrm{ADB} / \mathrm{OSM}$ for impurity profiling in tablet formulation by online Acquity QDa mass detector coupled with PDA detector, which simplifies the identification and evaluation of Impurities and can also screen the coelution. The developed method was validated as per ICH guidelines [19]. Besides, major potential degradation product in accelerated stability condition sample was identified by QDa mass detector and characterized by LC-MS-MS analytical techniques. The chemical structures of ADB/OSM and their known related substances with mass number were shown in Figure 1a and Figure-1b.

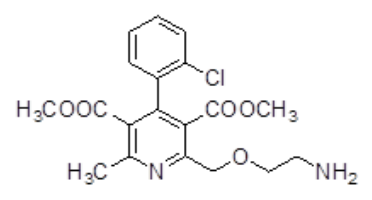

Amlodipine Methylester analog $(\operatorname{Imp}-4)$ $\mathrm{C}_{19} \mathrm{H}_{21} \mathrm{ClN}_{2} \mathrm{O}_{5}$

Amlodipine Besyalate $\mathrm{C}_{2} \mathrm{H}_{31} \mathrm{CIN}_{2} \mathrm{O}_{8} \mathrm{~S}$

Exact Mass: 566.15<smiles>CCOC(=O)C1=C(COCCN)NC(COCCN)=C(C(=O)OCC)C1c1ccccc1Cl</smiles>

Aminoethoxy Amlodipone (Im p-2) $\mathrm{C}_{22} \mathrm{H}_{30} \mathrm{ClN}_{3} \mathrm{O}_{6}$

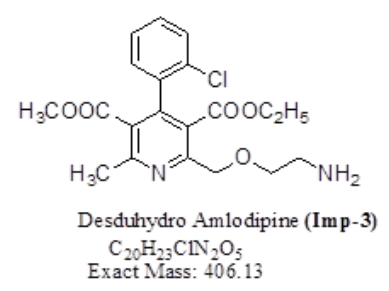<smiles>O=S(=O)(O)c1ccccc1</smiles>

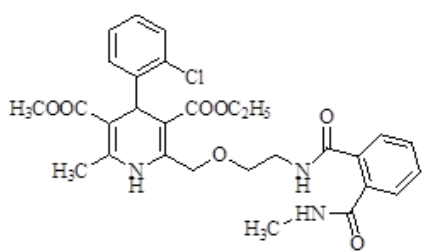

Methylanimo Phthalolyl Amlodipine (Imp-7) $\mathrm{C}_{29} \mathrm{H}_{32} \mathrm{ClN}_{3} \mathrm{O}_{7}$ Exact Mass: 569.19

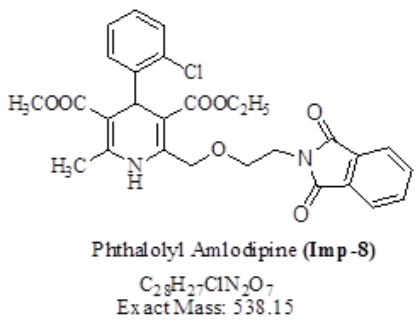

Fig-1a: Chemical structures of Amlodipine Besylate and its impurities. Impurities numbering was given according to their elution pattern 

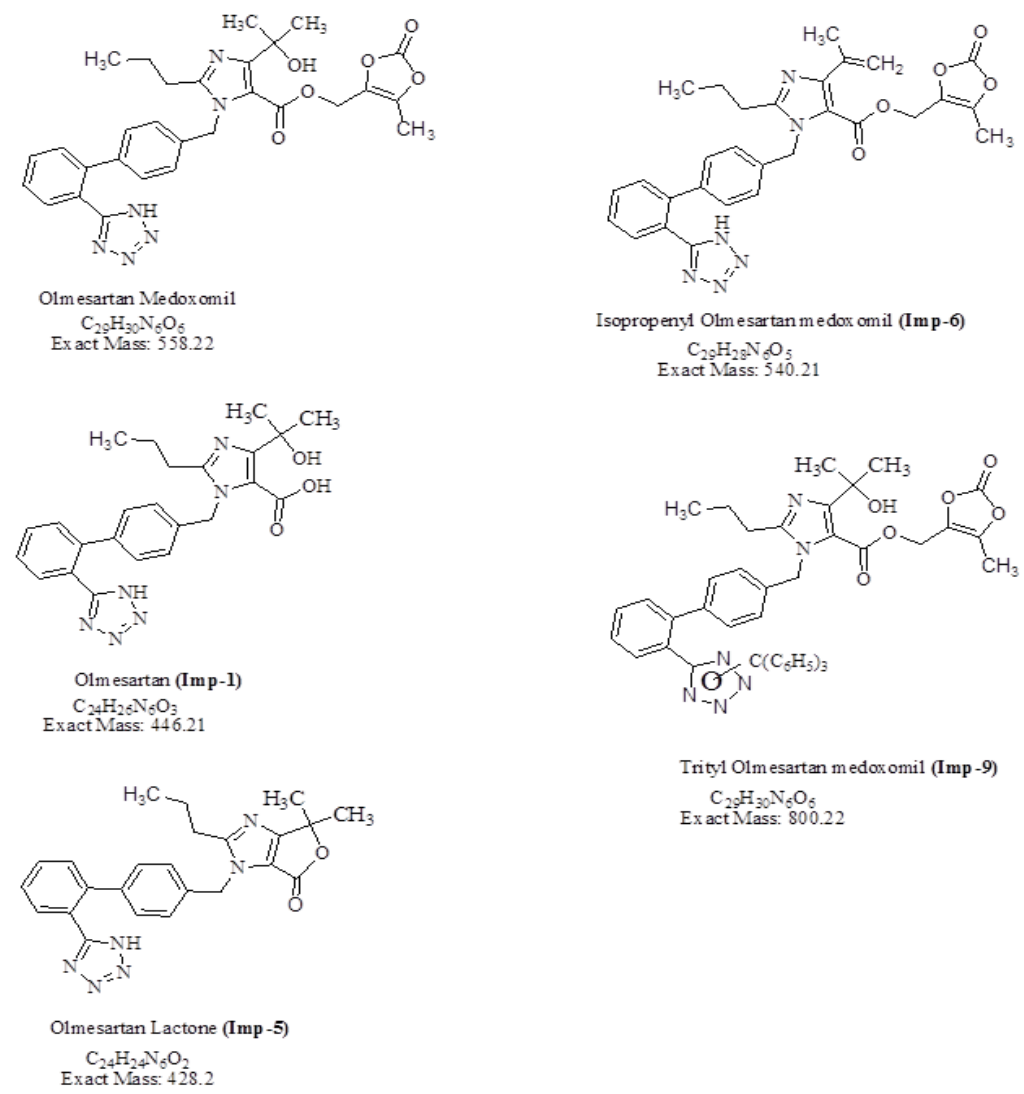

Trityl O1m esartan medox omil (Imp-9)
$\mathrm{C}_{20} \mathrm{H}_{30} \mathrm{~N}_{6} \mathrm{O}_{6}$
Ex act Mass: 800.22

Exact Mass: 428.2

Fig-1b: Chemical structures of Olmesartan Medoxomil and its impurities. Impurities numbering was given according to their elution pattern

\section{EXPERIMENTAL}

\section{Standards and Reagents}

All Standards and impurities, Amlodipine Besylate (ADB, purity of $99.5 \%$ ), Olmesartan medoxomil (OSM, purity of 99.0\%), Olmesartan (Imp1) (purity $94.8 \%$ ), Amino ethoxy amlodipine (Imp-2) (purity 99.48\%), Desdihydro Amlodipine (Imp-3) (purity 83.2\%), Amlodipine methyl ester analog (Imp4) (purity 87.73\%), Olmesartan Lactone (Imp-5) (purity 97.1\%), Isopropenyl Olmesartan medoximol (Imp-6) (purity 77.1\%), Methylamino PhthalolylAmlodipine (Imp-7) (purity 92.07\%), PhthalolylAmlodipine (Imp-8) (purity 98.68\%), Trityl Olmesartan medoxomil (Imp-9) (purity 93.9\%) and Tablet dosage forms were provided by Aurobindo Pharma Research Centre (Hyderabad, India). Chemicals used were of analytical grade and solvents were HPLC grade. Ammonium formate (ACS grade), Methanol (HPLC grade), Acetonitrile (HPLC grade) and Formic acid (AR grade) used in the mobile phase preparation were procured from Merck (Mumbai, India). Hydrochloric acid (AR Grade), Sodium Hydroxide (AR Grade) and Hydrogen peroxide (AR Grade) were procured from Rankem (Mumbai, India).

\section{Ammonium Formate Buffer (pH 3.4)}

$10 \mathrm{mM}$ ammonium formate buffer was prepared in water and adjusted $\mathrm{pH}$ to 3.4 with formic acid. Filtered through $0.45 \mu$ membrane filter (Millipore PVDF, Mumbai).

\section{Diluent}

$0.2 \%$ Formic acid was prepared in water and filtered through $0.45 \mu$ membrane filter (Millipore PVDF, Mumbai). The resultant solution and acetonitrile were mixed in the ratio of $65: 35 \mathrm{v} / \mathrm{v}$.

\section{Instrumentation}

Chromatographic separations were performed on Waters HPLC system (Waters Corp, Milford, MA, USA) equipped with quaternary pump, auto sampler, online degasser, PDA detector (Waters, 2998, USA) and a rheodyne injector with a $100 \mu \mathrm{L}$ injector loop (Waters, USA). The separation was achieved on Octadecyl stationary phase with $250 \mathrm{~mm} \times 4.6 \mathrm{~mm}$ dimension having $5 \mu \mathrm{m}$ particle size (ACE Technologies, UK). Waters Empower-3 data handling system was used to data acquisition and processing.

ACQUITY QDa mass detector (Waters, USA) connected to PDA detector (e2998, Waters, USA) in sequence on Waters alliance HPLC system was used. The liquid chromatography (LC) hyphenated with mass spectrometry (LC-TOF-MS) (Waters micro mass, Manchester, UK) operated with MassLynks (Version 4.1) software was used. The fragmentation profile of 
the sample was established by carrying out MS/TOF studies in positive electro spray ionization (+ve ESI) mode. Evoqua Water Technologies System (Ultra clear GP, Germany) was used for high quality HPLC grade water and filtered through $0.22 \mu \mathrm{m}$ filter.

Photo-stability studies were carried using Neutronic Photo-stability Chamber (Neutronic lifecare equipment Pvt. Ltd., India). The thermal degradation studies were carried in the Neutronic laboratory oven (Neutronic lifecare equipment Pvt. Ltd., India). Ultrasonic bath (PCi analytics, India) was used to dissolve the samples and $\mathrm{pH}$ meter (Thermo Scientific, Orine star series, India) was used to adjust the $\mathrm{pH}$ of the buffer for mobile phase. Sartorius analytical balance (Sartorius analytical lab, Germany) was used for weighing materials.

\section{Chromatographic conditions (HPLC-UV)}

Chromatographic study was conducted on octadecyl column with dimension $250 \mathrm{~mm}$ length and $4.6 \mathrm{~mm}$ diameter having $5 \mu \mathrm{m}$ pore size using $\mathrm{pH} 3.4$ formate buffer as mobile phase $\mathrm{A}$ and methanol and acetonitrile in the ratio of 70:30 (\% v/v) as Mobile phase B with Injection volume $20 \mu \mathrm{L}$ at flow rate 1.0 $\mathrm{mL} / \mathrm{min}$ maintaining column oven temperature at $35^{\circ} \mathrm{C}$. Based on the spectral maximum characteristics of standards and impurities of both analytes UV wavelength of $237 \mathrm{~nm}$ was selected for quantification. Gradient pump mode was used for effective separation with the program as follows: Time ${ }_{(\min )} / \mathrm{A}(\mathrm{v} / \mathrm{v}): \mathrm{B}(\mathrm{v} / \mathrm{v})$; $\mathrm{T}_{0.01} / 55: 45, \mathrm{~T}_{20} / 55: 45, \mathrm{~T}_{40} / 25: 75, \mathrm{~T}_{50} / 89: 11, \mathrm{~T}_{50} / 10: 90$, $\mathrm{T}_{54} / 15: 85, \quad \mathrm{~T}_{62} / 55: 45, \quad \mathrm{~T}_{70} / 55: 45$. Seeking good equilibrium, the analysis was usually performed after passing $50-60 \mathrm{~mL}$ of the mobile phase initially for conditioning and pre-washing of the stationary phase. For data interpretation and processing was made by using HPLC empower-3 software.

\section{PDA-QDa Mass detector conditions (HPLC-PDA- QDa)}

ACQUITY ESI QDa mass detector is connected in same workflow with Photo diode array Detector (PDA) detector, used for identification and quantification of known and unknown impurities formed during stability and forced degradation studies. For optical wavelength scanning from $200 \mathrm{~nm}$ to 400 $\mathrm{nm}$ was used for detector-1 (PDA detector) and ESI+ Ionization mode with both positive and negative modes was for QDa detector with operation parameters: probe temperature $600{ }^{\circ} \mathrm{C}$, capillary voltage was $0.8 \mathrm{kv}$, acquisition type was full scan m/z 200-1200 (centroid) and cone voltage was $15 \mathrm{v}$ were used.

\section{LC-MS and MS/MS analysis}

The liquid chromatography hyphenated with time-of-flight mass spectrometer (LC-TOF-MS) (Waters micro mass, Manchester, UK) operated with MassLynks (Version 4.1) software. The LC-MS separation was conducted under same conditions those used for the HPLC-PDA-QDa using volatile buffer 10 $\mathrm{mM}$ ammonium formate buffer adjusting $\mathrm{pH} 3.4$ with formic acid. Nitrogen was used with flow rates of $20 \mathrm{l} / \mathrm{h}$ and $4001 / \mathrm{h}$ for nebulization and desolvation respectively. The fragmentation profile of the sample was established by carrying out MS/TOF studies in positive electro spray ionization (+ve ESI) mode and with following mass parameters: hexapole RF, capillary voltage of $3000 \mathrm{v}$, cone voltage of $25 \mathrm{v}$, source temperature at $120^{\circ} \mathrm{C}$, desolvation temperature at $300^{\circ} \mathrm{C}$, ion energy with $1.0 \mathrm{v}$ and collision energy was set to $8 \mathrm{v}$ for MS measurement and $25 \mathrm{v}$ for the MS/MS measurement. For the MS/MS operation, argon was used as a collision gas. Mass spectra were acquired over at $\mathrm{m} / \mathrm{z}$ rang of $50-2000$.

\section{Standard Solutions}

Separate ADB $(0.35 \mathrm{mg} / \mathrm{mL})$ and OSM $(0.5 \mathrm{mg}$ $/ \mathrm{mL}$ ) standard stock solutions were prepared by dissolving in acetonitrile and further diluted with diluent to get appropriate concentration. All standard stock standard solutions were freshly prepared and stored in the refrigerator during analysis.

\section{Stress Degradation Studies}

Degradation studies were carried out on ADB/OSM tablet product as per ICH guidelines ( $\mathrm{ICH}$, Q1A (R2) 2005) under prescribed stress conditions. As per ICH guidelines [20], the stress degradation studies were conducted to determine the stability of drug substance or drug product by knowing the degradation pathways to identify the possible degradation products, under a variety of stress conditions like hydrolysis, oxidation, light, moisture/heat and dry heat. Multiple stressed samples were prepared as indicated below. They were chromatographed along with a non-stress sample.

In Acid and Base-induced degradations, sample solution containing equivalent to $250 \mu \mathrm{g} / \mathrm{mL}$ of $\mathrm{ADB}$ in product was treated with $1 \mathrm{M}$ hydrochloric acid $(\mathrm{HCl})$ at $85{ }^{\circ} \mathrm{C}$ in water bath and $0.2 \mathrm{M}$ sodium hydroxide $(\mathrm{NaOH})$ respectively. The solutions were neutralized as needed $(1 \mathrm{M} \mathrm{NaOH}$ or $0.2 \mathrm{M} \mathrm{HCl})$. For Oxidative condition (Hydrogen peroxide-induced degradation), sample solution containing $250 \mu \mathrm{g} / \mathrm{mL}$ equivalent of $\mathrm{ADB}$ in product was treated with $5 \% \mathrm{v} / \mathrm{v}$ $\mathrm{H}_{2} \mathrm{O}_{2}$ at $85{ }^{\circ} \mathrm{C}$ in water bath. During thermal degradation study, sample was subjected to dry heat in hot air oven at $105{ }^{\circ} \mathrm{C}$ and similarly in humidity exposure, sample was subjected to $90 \%$ relative humidity $(\mathrm{RH})$ at $25{ }^{\circ} \mathrm{C}$. The detailed conditions were indicated in Table-1. As per guidelines for photostability testing of new drug substances and products, samples should be exposed to light providing an overall illumination of not less than 1.2 million lux hours and an integrated near ultraviolet energy of not less than $200 \mathrm{Wh} / \mathrm{m} 2$ and indicated in Table- 1 . 
Similarly placebo was also treated in same way as sample treated above in each conditions separately. All these stressed samples and placebos analysed by HPLC for the appearance of additional impurities which were identified on the basis of respective placebos.

\section{ANALYSIS OF PHARMACEUTICAL FORMULATIONS \\ Samples and Placebo Preparation}

Not less than 10 tablets were weighed and crushed into a fine powder in motor and pestle and transferred an equivalent portion of powder about 25 $\mathrm{mg}$ of $\mathrm{ADB}$ and prepared uniform solution by sonication for not less than 20-25 minutes and maintaining the bath temperature between $20-25^{\circ} \mathrm{C}$ with intermittent shaking. Allowed the solution to cool to room temperature and diluted to volume with diluent and mixed. Filtered the sample solution through $0.45 \mu$ Millipore PVDF membrane filter by discarding the first $3 \mathrm{~mL}$ of filtrate and used as such sample solution. Weighed and transferred accurately a quantity of placebo powder equivalent to about $25 \mathrm{mg}$ of $\mathrm{ADB}$ and prepared same as that of sample preparation

\section{RESULTS AND DISCUSSION}

The main aim of this chromatographic method was to achieve the resolution among known related substances, unknown degradation products and main components. Detection and quantification carried out by synergetic effect of PDA with QDa mass detector. A spiked sample containing $250 \mathrm{ppm}$ for ADB and 1000 ppm for OSM and $0.2 \%$ level of their known impurities was used for method development. The possible impurities or related substances of $\mathrm{ADB}$ and OSM resemble to their respective drug substances, it is clear from the molecular structures (Figure $1 \mathrm{a}$ and $1 \mathrm{~b}$ ) that all the related compounds of $\mathrm{ADB}$ are basic in nature and of OSM are weakly acidic in nature. In order to get better separation and detection of related substances and degradation products of both ADB and OSM, the HPLC conditions were optimized through different systematic trails. To obtain selectivity, specificity and optimum resolution among all peaks, mid-polar to nonpolar column stationary chemistry phases like phenyl, $\mathrm{C}_{8}$ and $\mathrm{C}_{18}$ were used of different makes using organic modifiers like Methanol and Acetonitrile and various $\mathrm{pH}$ of buffer were tested.

\section{Selection of Stationary Phase}

The fixing of column play key role to separate the all analytes in combination products. Based on their molecular properties and $\mathrm{pKa}$ values initial method optimization was evaluated with phenyl, Octyl and octyldecyl stationary phase. Moderate separation was achieved with poor resolution of Imp-2 and Imp-3 and with known \& unknown impurities and asymmetrical peak shapes were observed for the few known impurities and main analytes with phenyl and octyl stationary phases, reason is that analytes are interact with silanol groups. Separation among other peaks were satisfactory with more symmetrical peaks were observed more nonpolar stationary phase octyldecyl, implies that octyldecyl stationary phased is more suitable for this application. Hence, to retain the analytes and to improve the peak shapes more nonpolar nature of stationary phase octyldecyl with different manufacturers makes like G.L Sciences Inc, UK, Zorbax Agilent, USA, Kromasil, UK, ACE, UK were chosen for separation by using different phosphate/formate buffer mobile phases. Among all makes, octyldecyl stationary phase manufactured by ACE make given good separation with more symmetrical shapes and resolution improved between imp-2 and imp-3 and Imp-5 and ADB and separation between ADB and OSM also satisfactory. In addition to stationary phase, $\mathrm{pH}$ of mobile phase and concentration of organic modifier also play very impotent key role which leads to better separation.

\section{Influence of Organic Modifier}

Based on the solubility of respective drug substances, initially the methanol and acetonitrile $(50: 50 \% \mathrm{v} / \mathrm{v})$ was used as organic modifier which leads to the poor resolution between Imp-2 and Imp-3 as well as ADB and OSM main peaks. It may be due to the high solvent strength of acetonitrile. To improve the resolution among the peaks, organic modifier ratio of methanol and acetonitrile (70:30\%v/v) was also tried. Separation among the peaks was improved with good peak shape. The base line was found good and response for all components was improved in this ratio.

\section{Influence of $\mathrm{pH}$ of Mobile Phase Buffer and Gradient Elution \\ Due to the significant difference in the} physical and chemical properties of both drug substances and their impurities in fixed dose combination product, the fixing of suitable $\mathrm{pH}$ of buffer play key role in reproducible retention for analytes. The acid dissociation constants (pKa) of ADB is about 9.45 and for OSM about 5.57 when observe the molecular structures of both drug substances (Fig. 1a and 1b) primary amine functional group present in ADB indicates that there would be probable secondary silanol effect with column silica when method uses alkaline mobile phase which may lead to peak tailing. At low $\mathrm{pH}$ of buffer condition, the ionization of the amine moieties present on the analytes molecule is suppressed. For this one of trail purpose, trifluroacetic acid buffer was used, with this both ADB and OSM has poor resolution, implies very low $\mathrm{pH}$ is not right choice for the development. Hence further trials were taken using potassium phosphate and ammonium formate buffers, the retention time and separation of known impurities and unknown impurities of both components were selective with $\mathrm{pH}$ of phosphate and ammonium formate buffers and no co-elution was observed. Advantage of 
ammonium formate buffer is that it volatile and compatible with mass detector hence ammonium formate buffer with pH's from 2.8 to 4.5 was chosen and monitored the movement and improvement of separation among the analytes using gradient program $\left((\mathrm{min}) / \mathrm{A} \quad(\mathrm{v} / \mathrm{v}): \mathrm{B} \quad(\mathrm{v} / \mathrm{v}) ; \mathrm{T} \quad 0.01 / 50: 50, \mathrm{~T}_{18} / 50: 50\right.$, $\left.\mathrm{T}_{40} / 22: 78, \mathrm{~T}_{50} / 10: 90, \mathrm{~T}_{54} / 10: 90, \mathrm{~T}_{62} / 50: 50, \mathrm{~T}_{70} / 50: 50\right)$ with $1.0 \mathrm{~mL} /$ minute flow rate. In this gradient programme, Imp-1 and Imp-2 were co-eluted each other and poor separation among ADB, OSM, Imp-6 and Imp-7 was observed. From various chromatographic conditions trials method was optimized for symmetrical, acceptable resolution among the peaks and excellent selectivity was achieved and finalized the following method conditions: $10 \mathrm{mM}$ formate buffer of pH 3.4 condition on ACE $5 \mathrm{C} 18,250 \mathrm{~mm}$ x $4.6 \mathrm{~mm}$, $5 \mu \mathrm{m}$ using methanol and acetonitrile the ratio of $70: 30 \% \mathrm{v} / \mathrm{v}$ as organic modifier using other slow gradient program $\left((\min ) / \mathrm{A}(\mathrm{v} / \mathrm{v}): \mathrm{B}(\mathrm{v} / \mathrm{v}) ; \mathrm{T}_{0.01} / 55: 45\right.$, $\mathrm{T}_{20} / 55: 45, \mathrm{~T}_{40} / 25: 75, \mathrm{~T}_{50} / 10: 90, \mathrm{~T}_{54} / 15: 85, \mathrm{~T}_{62} / 55: 45$, $\mathrm{T}_{70} / 55: 45$ ) at $1.0 \mathrm{~mL} / \mathrm{minute}$ flow rate. The typical HPLC chromatogram of placebo solution and spiked sample with all known related substances given in Figure $2 \mathrm{a}$ and $2 \mathrm{~b}$ respectively and system suitability parameters for spiked sample were captured in Table- 2 .

\section{Wavelength Selection and Diluent Optimization}

All impurities of ADB show spectral absorption maxima at $\sim 237 \mathrm{~nm}$ whereas impurities of OSM show first maxima at $\sim 230 \mathrm{~nm}$ and second maxima at $\sim 250 \mathrm{~nm}$ (Figure-3). Hence, wavelength of intersect point at $237 \mathrm{~nm}$ has been chosen for the simultaneously quantification of impurities in ADB/OSM tablets. The wavelength at $237 \mathrm{~nm}$, satisfactory sensitivity and optimum responses was achieved. Drug components are partially soluble in water and soluble in organic solvents. For trial purpose, a degassed mixture of $0.2 \%$ formic acid in water and acetonitrile in the ratio of $65: 35 \mathrm{v} / \mathrm{v}$ was used. In this diluent, solubility and stability for impurities of both ADB and OSM are found to be satisfactory. Hence the same diluent was chosen for standard and sample preparations in the method development and validation activity.
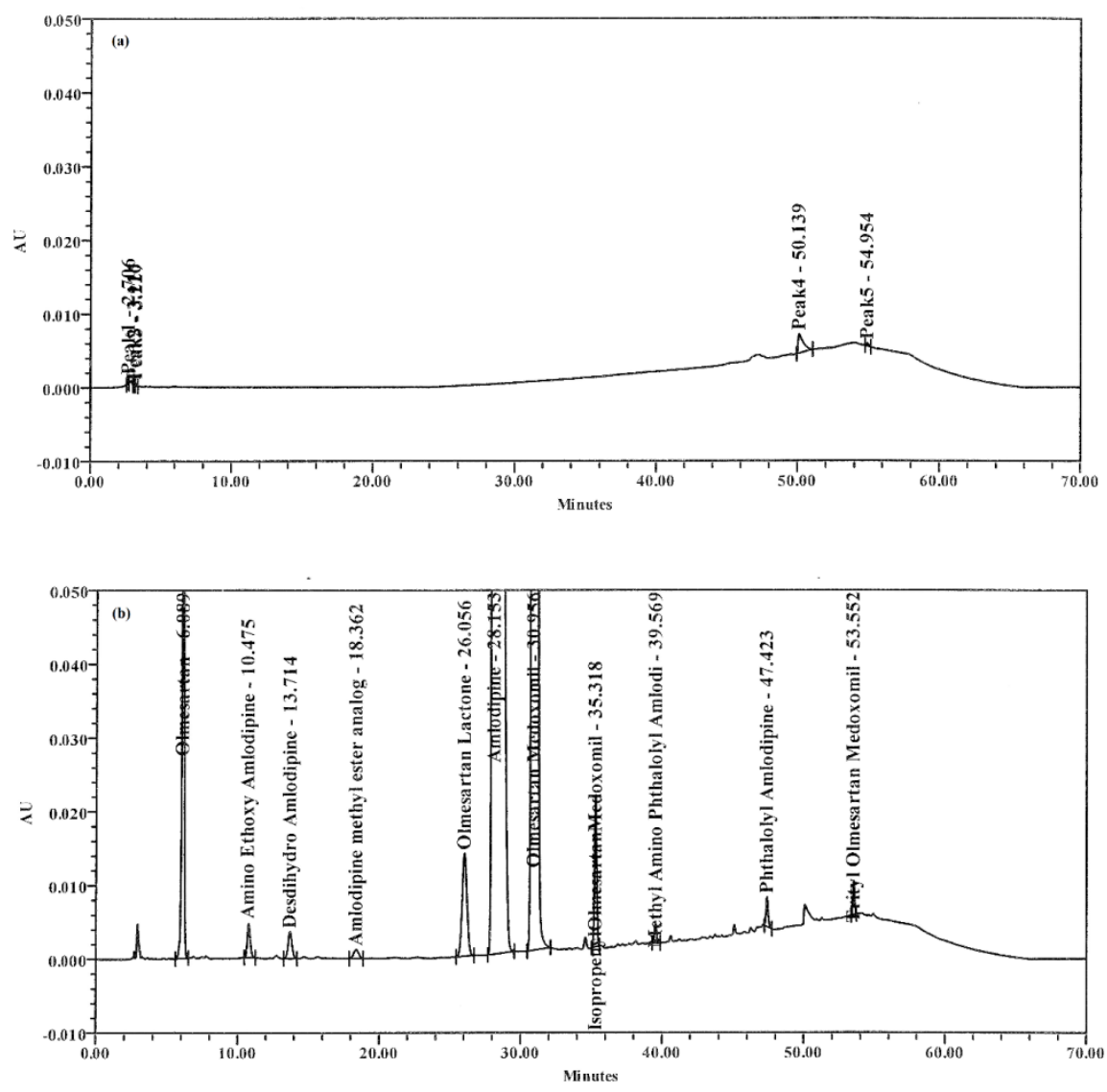

Fig-2: Typical HPLC chromatograms of (a) Placebo solution and (b) Spiked sample with all known impurities 

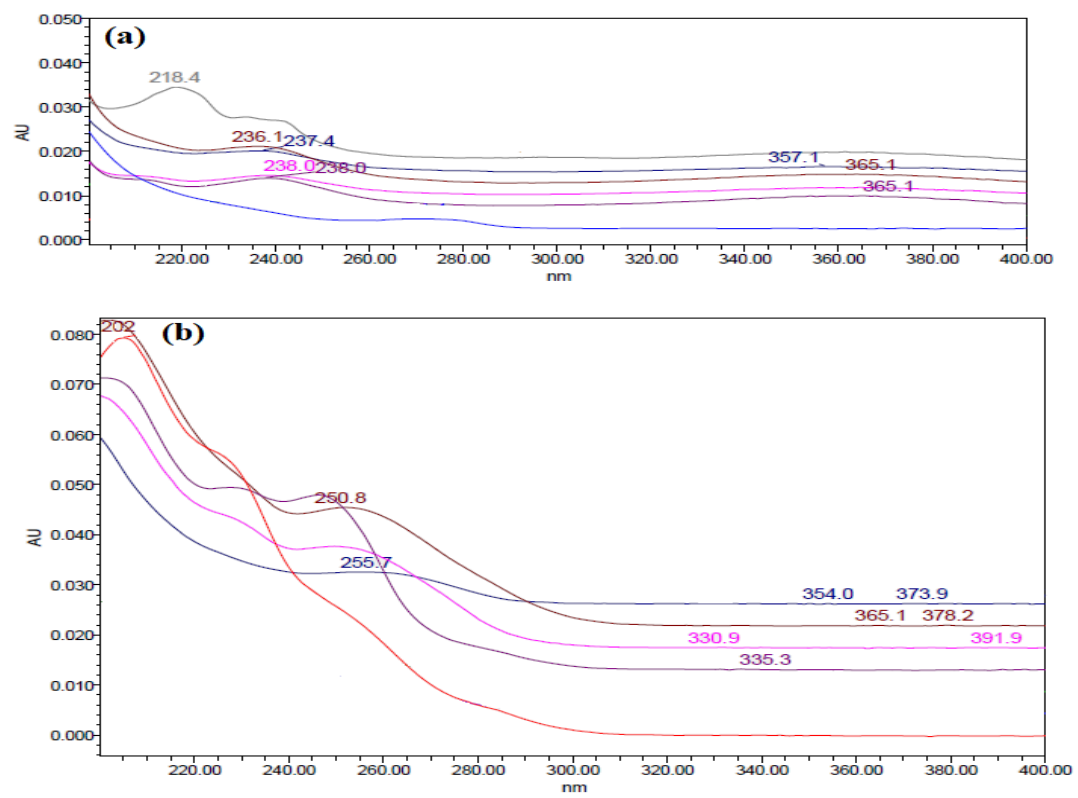

Fig-3: UV-Visible spectra's of (a) ADB and its impurities and (b) OSM and its impurities

Table-2: Results of system suitability testing parameters for spiked sample with known impurities

\begin{tabular}{|c|c|c|c|c|c|c|}
\hline Analytes & $\begin{array}{l}\text { RT } \\
\text { (Min) }\end{array}$ & RRT* & $\begin{array}{l}\text { Resolution } \\
\text { (Rs)** }\end{array}$ & $\begin{array}{l}\text { Tailing factor } \\
\text { (T) }\end{array}$ & $\begin{array}{l}\text { Capacity } \\
\text { Factor } \\
\left(k^{\prime}\right)\end{array}$ & $\begin{array}{l}\text { Plate count } \\
(\mathrm{N})\end{array}$ \\
\hline Un retained peak (System peak) & 2.7 & --- & --- & --- & 26 & --- \\
\hline Olmesartan (Imp-1) & 6.08 & 0.20 & --- & 1.1 & 60 & 8079 \\
\hline Aminoethoxy Amlodipine (Imp-2) & 10.48 & 0.34 & 9.8 & 1.1 & 105 & 5381 \\
\hline Desdihydro Amlodipine (Imp-3) & 13.72 & 0.44 & 5.6 & 1.1 & 138 & 10310 \\
\hline $\begin{array}{l}\text { Amlodipine methyl ester analog } \\
\text { (Imp-4) }\end{array}$ & 18.36 & 0.59 & 8.1 & 1.0 & 185 & 12049 \\
\hline Olmesartan lactone (Imp-5) & 26.05 & 0.84 & 12.4 & 1.0 & 263 & 29724 \\
\hline Amlodipine & 28.15 & 0.91 & 2.7 & 1.5 & 284 & 14614 \\
\hline Olmesartan Medoxomil & 30.95 & 1.00 & 4.0 & 0.9 & 310 & 119732 \\
\hline $\begin{array}{ll}\text { Isopropenyl } & \text { Olmesartan } \\
\text { Medoxomil (Imp-6) } & \\
\end{array}$ & 35.31 & 1.14 & 12.2 & 1.0 & 353 & 224905 \\
\hline $\begin{array}{lll}\text { Methyl amino } & \text { Phthalolyl } \\
\text { Amlodipine (Imp-7) } & \\
\end{array}$ & 39.56 & 1.28 & 14.1 & 1.1 & 396 & 287652 \\
\hline Phthalolyl Amlodipine (Imp-8) & 47.42 & 1.53 & 27.1 & 1.1 & 476 & 473716 \\
\hline $\begin{array}{l}\text { Trityl Olmesartan Medoxomil } \\
\text { (Imp-9) }\end{array}$ & 53.55 & 1.73 & 23.8 & 1.0 & 538 & 955921 \\
\hline
\end{tabular}

*RRTs of impurities established with respect to OSM main peak
** Resolution determined between each analyte peak and previous one

\section{Detection of impurities by HPLC}

During accelerated stability $\left(3 \mathrm{M}, 45^{\circ} \mathrm{C} / 75 \%\right.$ $\mathrm{RH})$ evaluation of ADB /OSM tablet dosage form in PVC and PVC/PVDC and blister Container closure packing material as per ICH guidelines Q1A (R2) [20], three main impurities were detected when analysed by developed HPLC method. Out of that, impurity at 6.10 min was corresponding to Olmesartan (Imp-1), impurity at 13.74 min was defined as Deshydro amlodipine (Imp-3) and an impurity at 38.09 min was above at $0.32 \%$ level in sample. This impurity does not correspond to any of the known impurities of ADB /OSM drug substances. This impurity was consistently increasing in accelerated stability condition samples. This impurity named as Unkown-1 and a typical HPLC Chromatogram depicted in Figure 4a. As this was the unknown it is necessary to identify the nature of these unknown impurities in finished dosage forms as per regulatory guidelines.

\section{PDA-QDa Mass Detection Analysis}

To evaluate unknown-1 formed consistently in stability samples, PDA-QDa mass detection was carried out. ESI QDa scan was recorded in both positive and negative ion mode. However, positive ion mode produced most intense and stable MS spectrum for Unknown-1in accelerated stability condition sample. 
The positive ion ESI QDa spectrum of unknown-1 showed $[\mathrm{M}+\mathrm{H}]^{+}$ion peak at $\mathrm{m} / \mathrm{z} 875.5$ predominantly and optical spectrum shows similar spectrum of OLM. The QDa mass spectra for unknown-1 at 38.09 min was shown in Figure 4b. As the spectrum alone is not conclusive to identify the nature of the molecule as the spectrum of unknown -1 is not distinctive. Hence, this coupled detection approach significantly enhanced analytical value, minimize the risk of unexpected coelutions and eliminates the tedious multiple alternative analytical tasks as spectral identification and mass identification can be evaluated simultaneously in single analytical run.
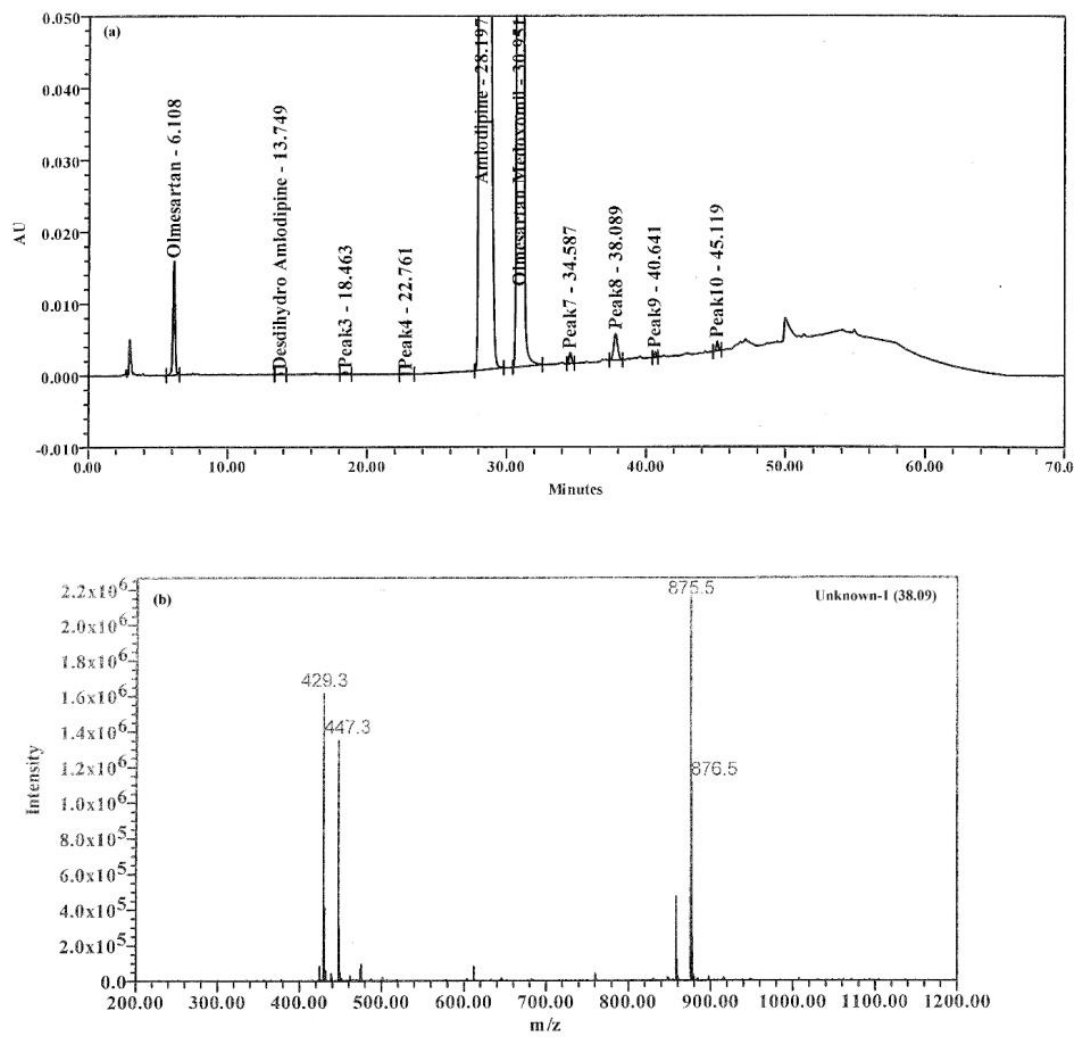

Fig-4(a): Typical HPLC chromatogram of ADB/OSM tablets stability sample with Unknown impurity-1 (RT 38.08 min) (b) Typical QDa mass spectra for Unknown impurity-1 (RT 38.08 min)

\section{LC-MS-MS analysis and Structure elucidation of impurity}

From the PDA-QDa mass detector online coupling technique assessment, the unknown-1 was confirmed impurity of OSM based on the PDA spectral characteristics and QDa mass detector shows $\mathrm{m} / \mathrm{z}$ 875.5 which is nearest double the theoretical mass of OSM (m/z 558). Hence, confirmed dimerization of OSM have certain possibility and ruled out the dimerization of ADB. However, detailed structural elucidation of this major unknown-1 was carried out on TOF-MS analysis. The TOF-MS data showed that the molecular ion of unknown-1was 875.4133. The fragments at $\mathrm{m} / \mathrm{z} 857.4008,207.0921,235.0982$, 429.2037 and 448.2168 were appeared in MS/MS analysis (Figure 5). Due to loss of water (18 Da) fragment in MS/MS, fragment at $\mathrm{m} / \mathrm{z} 857.4008$ was appeared. Fragment pattern of $\mathrm{m} / \mathrm{z} 448.2037$ was corresponding to Olmesartan (Imp-1) and the fragment at $\mathrm{m} / \mathrm{z} 429.2037$ was assigned to Olmesartan lactone (Imp-5). The MS/MS fragment of Unknown-1 at $\mathrm{m} / \mathrm{z}$ 207.0921 and 235.0982 were also observed in the MS/MS spectrum of OSM compound. This MS spectral data manifested that molecular mass of Unknown-1 and all daughter ion fragment contains odd number of nitrogen atoms. In order to determine the molecular formula of impurity, figures of measured accurate masses were fed into elemental composition calculator. Reasonable limits i.e. carbon 0-47, hydrogen 0-52, nitrogen $0-13$ and oxygen $0-5$ was set. The search revealed several theoretically possible molecular formulae. The closest possible molecular formula for protonated molecular ion was selected on the basis of lowest difference in mass between theoretical and observed values. Hence Unknown-1 was confirmed and concluded as dimer by the fragment ions which were in accordance with literature data of Olmesartan medoximol dimerization [21]. Hence from literature source and information based on tablet formulation process, a key excipient; magnesium stearate was taken into account to proceed for impurity structure elucidation. From this MS spectral data and literature information, Unknown-1 was attributed to be a dehydrated condensation product of two OSM molecules under influence of magnesium stearate which is excipient, accelerate the degradation reaction in 
ADB/OSM fixed dose combination tablets. Hence, this unknown-1 was postulated as an esterified dimer of two molecules of OSM in ADB/OSM fixed dose tablets and this impurity was observed more in the poly vinyl chloride (PVC) and PVC/PVDC container closer system containing formulation and significantly less in the Blister packed formulations and the plausible reaction was proposed as shown in Figure-6.
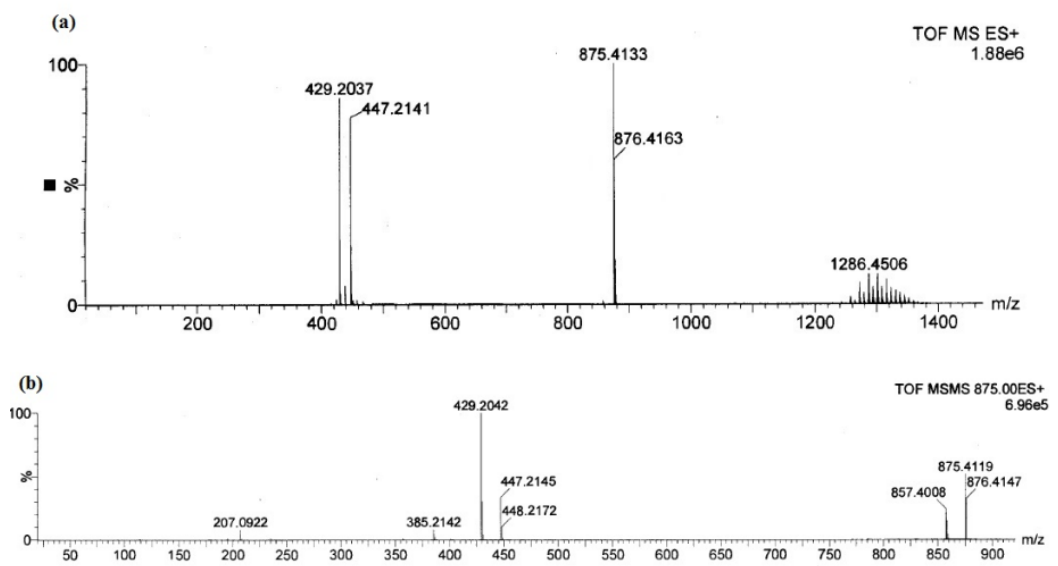

Fig-5: MS and MS/MS data of 38.08 min RT unknown-1 (a) Mass spectrum of unknown impurity-1, (b) MS/MS spectrum of unknown-1

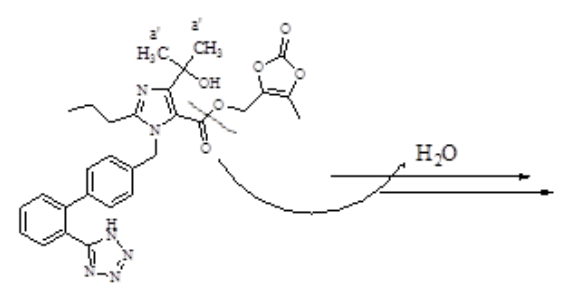

Olmesart an Med oxomil

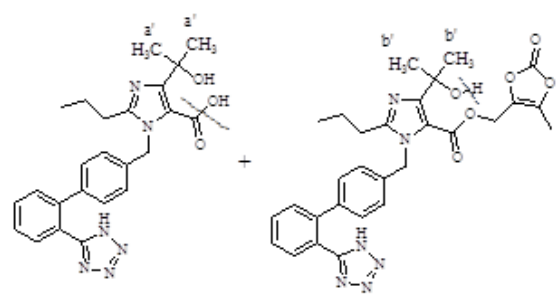

Olmesar tan Medor omil

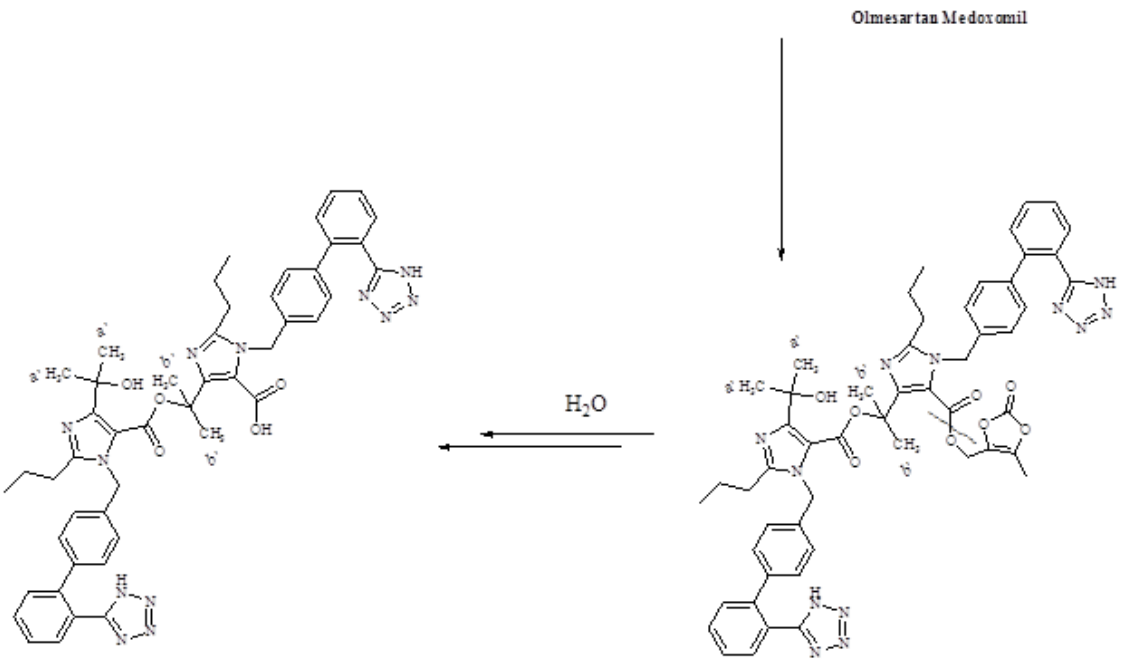

Olmesar tan Dimer im purity

Fig-6: Scheme for formation of unknown impurity of OSM in ADB/OSM fixed dose tablets

\section{VALIDATION}

The developed HPLC method of related substances was validated according to ICH guidelines [19] to demonstrate suitability indicating nature for the intended purpose with parameters like System suitability, specificity, accuracy, precision (repeatability and intermediate precision), linearity, stability of solution and robustness were assessed. The system suitability tests [22] are an integral part of liquid chromatographic methods in the course of optimizing the conditions of the proposed method. System suitability parameters with respect to resolution, tailing factor, capacity factor, theoretical plates, retention time, relative retention time and percentage relative standard 
deviation (\%RSD) were assessed by injecting a blank followed by standard solution $(n=6)$. \% RSD of peak area of standard was determined and the results obtained are all well within acceptable limits (acceptance limit \% RSD <5) and given in Table-3.

Table-3: System suitability testing parameters and statistical parameters of standard solution

\begin{tabular}{|l|l|l|}
\hline Parameter & ADB & OSM \\
\hline Retention time (min) & 28.82 & 31.05 \\
\hline Relative Retention Time (RRT)\# & 0.91 & 1.00 \\
\hline Capacity factor (k) & 281 & 312 \\
\hline USP plate count (N) & 64376 & 111675 \\
\hline USP Tailing factor (T) & 1.0 & 1.0 \\
\hline USP resolution (Rs)* & --- & 5.3 \\
\hline Mean Area** & 278518 & 220913 \\
\hline (\%) RSD & 0.3 & 0.3 \\
\hline 95\% Confidence Interval ( $)$ ) & 803 & 762 \\
\hline \multicolumn{3}{|c|}{ \#RRT was calculated with respect to OSM } \\
*Resolution between ADB and OSM \\
**Mean from six replicate injections of standard solution
\end{tabular}

\section{Specificity and forced degradation}

Specificity is the ability of the analytical method to measure the analyte concentration accurately in the presence of all other potential impurities. Assessment of specificity experiment for ADB/OSM product was performed on water HPLC system with PDA detector under finalized Chromatographic conditions. Diluent, placebo, all known impurities of both $\mathrm{ADB}$ and OSM compounds and sample solutions were prepared on different stress conditions viz., Acid hydrolysis, Base hydrolysis, Oxidation, Thermal degradation, Humidity and Photolytic degradations. The peak purity indices for the analytes in stressed solutions were also determined with PDA detector [23] found to be better (purity angle < purity threshold) indicating that no additional peaks were co-eluting with the analytes and evidencing the ability of the method to assess unequivocally the analytes of interest in the presence of potential interference. All the degradation products were well from separated each other and the method was found to be specific and its results were summarized in Table-1.
As observed from liquid stress conditions, about $9-15 \%$ degradation were observed under acid, base, peroxide thermal and photolytic stress conditions. Apart from known impurities (Imp-1, Imp-2, Imp-3, Imp-5\& Imp-6), total seven major unknown impurities were observed under all stress conditions. These degradation products were analysed using QDa mass detector and $\mathrm{m} / \mathrm{z}$ ratio of these degradation products was determined. The molecular mass of unknown degradation products (DPs) observed in all stress conditions were identified and summarized in Table-4. As observed from the data, less degradation was observed under humidity stress condition, indicating that $\mathrm{ADB} / \mathrm{OSM}$ was stable under this stress condition. Based on QDa mass data, a systematic mechanism for the formation of degradation products was proposed based on the known reactivity of the respective drugs present in the formulation through stress conditions (Figure 7a and 7b). Therefore the use of LC-MS (QDa) can serve as an additional tool providing assessment of peak purity and impurity identification.
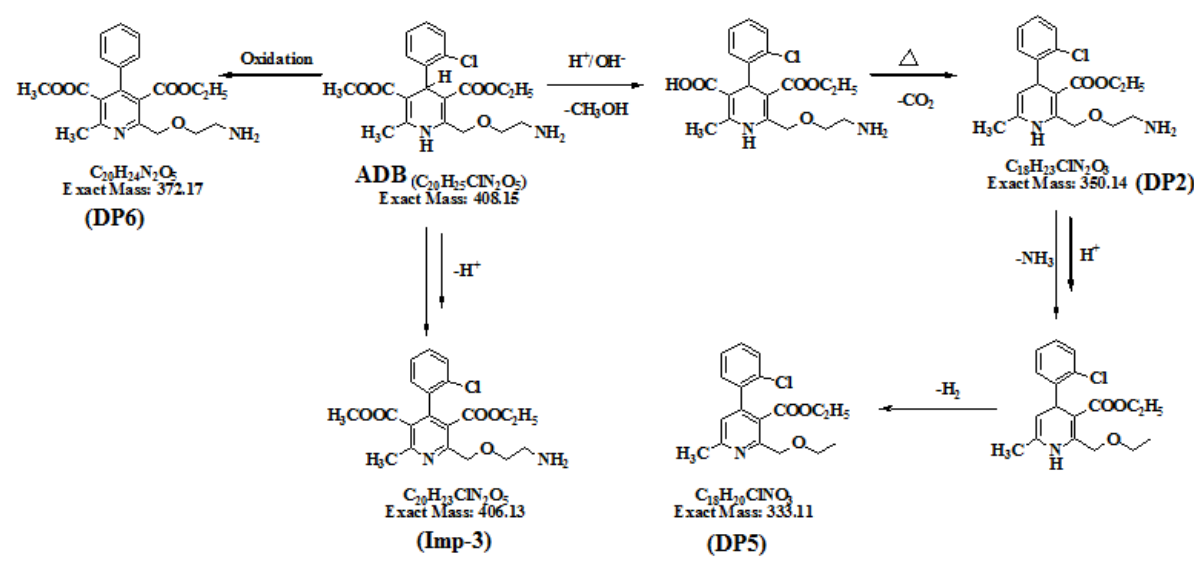

Fig-7a: Possible degradation path of ABD in ABD/OSM tablets under different stress conditions 


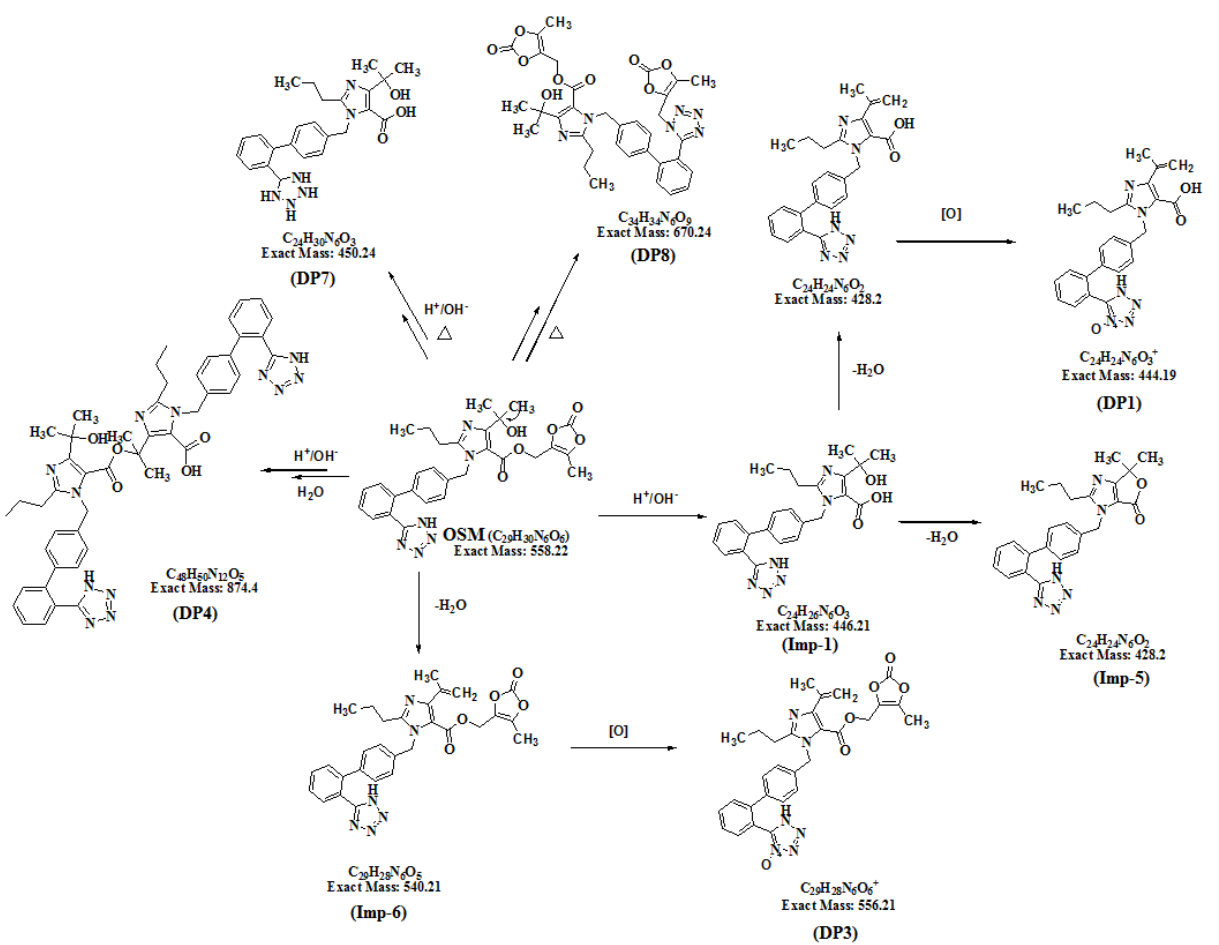

Fig-7b: Possible degradation path of OSM in ABD/OSM tablets under different stress conditions

Table-4: Acquity QDa Mass data for forced degradation studies of ADB/OSM tablet product (5/20mg)

\begin{tabular}{|c|c|c|c|c|}
\hline Degradation condition & $\begin{array}{l}\text { RT } \\
\text { (Min) }\end{array}$ & RRT & $\begin{array}{l}\text { Degradation products } \\
\text { (DPs) }\end{array}$ & $\begin{array}{l}\text { Mass of degradation } \\
\text { product }(\mathrm{M}+\mathrm{H})(\mathrm{m} / \mathrm{z})\end{array}$ \\
\hline Undegraded sample & 5.94 & 0.20 & Imp-1 & 447.31 \\
\hline \multirow[t]{8}{*}{ Acid degradation } & 5.96 & 0.20 & Imp-1 & 447.31 \\
\hline & 10.78 & 0.37 & DP1 & $445.34 * *$ \\
\hline & 12.89 & 0.44 & Imp-3 & 407.24 \\
\hline & 14.7 & 0.52 & DP2 & $351.19 *$ \\
\hline & 34.08 & 1.16 & Imp-6 & 541.32 \\
\hline & 36.03 & 1.24 & DP3 & $557.32 * *$ \\
\hline & 38.06 & 1.27 & DP4 & $875.5 * *$ \\
\hline & 47.63 & 1.63 & DP5 & $334.14 *$ \\
\hline \multirow[t]{5}{*}{ Base degradation } & 5.97 & 0.20 & Imp-1 & 447.31 \\
\hline & 12.92 & 0.45 & Imp-3 & 407.24 \\
\hline & 14.1 & 0.48 & DP6 & $374.24 *$ \\
\hline & 25.64 & 0.88 & Imp-5 & 429.31 \\
\hline & 36.83 & 1.26 & DP7 & $451.25 * *$ \\
\hline \multirow[t]{3}{*}{ Peroxide degradation } & 5.96 & 0.20 & Imp-1 & 447.31 \\
\hline & 13.33 & 0.45 & Imp-3 & 407.24 \\
\hline & 36.87 & 1.26 & DP7 & $451.21 * *$ \\
\hline \multirow[t]{4}{*}{ Humidity condition } & 5.93 & 0.20 & Imp-1 & 447.31 \\
\hline & 13.08 & 0.44 & Imp-3 & 407.25 \\
\hline & 36.87 & 1.21 & DP7 & $451.21 * *$ \\
\hline & 37.92 & 1.29 & DP4 & $875.5 * *$ \\
\hline \multirow[t]{4}{*}{ Thermal degradation } & 5.82 & 0.20 & Imp-1 & 447.31 \\
\hline & 34.01 & 1.17 & Imp-6 & 541.32 \\
\hline & 36.75 & 1.23 & DP7 & $451.21 * *$ \\
\hline & 39.79 & 1.40 & DP8 & $671.38 * *$ \\
\hline \multirow[t]{2}{*}{ Photolytic exposure } & 5.94 & 0.20 & Imp-1 & 447.31 \\
\hline & 36.79 & 1.22 & DP7 & $451.23 * *$ \\
\hline
\end{tabular}

*Belongs to Amlodipine Besylate, ** Belongs to Olmesartan Medoxomil 


\section{Linearity}

Linearity was performed for ADB, OSM and their related substances at eight concentration level in triplicates from LOQ concentration to $150 \%$ level to demonstrate detection capability of the method. The detailed concentration ranges were shown in Table 5 and linearity was performed by plotting the peak area of the analyte from the chromatogram were plotted against the respective concentration of analytes to obtain the Standard curve. The results were subjected to regression coefficient by linear least-square regression method. The regression coefficient exceeds 0.99 for all analytes which demonstrated good linear response for the impurities across the concentration range of interest. The regression statistics data were shown in Table 5. Furthermore linearity experiment data was used for the determination of LOD and LOQ concentration by using residual standard deviation $(\sigma)$ and slope (S) of calibration method and LOD and LOQ values were predicted using formula $3.3 \sigma /$ slope for LOD and $10 \sigma$ / slope for LOQ and established the LOD and LOQ precision $(n=6)$ at these predicted concentration levels. The results of all specified related substances of both ADB, OSM were summarized in Table-5.

Table-5: Results of Linearity and Method sensitivity parameters

\begin{tabular}{|l|l|l|l|l|l|}
\hline Analytes & Regression equation* & $\left.\mathbf{( r}^{\mathbf{2}}\right)$ & $\begin{array}{l}\text { Linearity range } \\
/(\boldsymbol{\mu g} / \mathbf{m L})\end{array}$ & $\begin{array}{l}\mathbf{L O D} / \\
(\boldsymbol{\mu g} / \mathbf{m L})\end{array}$ & $\begin{array}{l}\mathbf{L O Q} / \\
(\boldsymbol{\mu g} / \mathbf{m L})\end{array}$ \\
\hline Imp-1 & $\mathrm{Y}=61818 \mathrm{X}-2453$ & 0.9994 & $0.078-60.588$ & 0.026 & 0.078 \\
\hline Imp-2 & $\mathrm{Y}=32041 \mathrm{X}+107$ & 0.9992 & $0.162-3.688$ & 0.058 & 0.174 \\
\hline Imp-3 & $\mathrm{Y}=23508 \mathrm{X}-95$ & 0.9998 & $0.198-3.796$ & 0.065 & 0.198 \\
\hline Imp-4 & $\mathrm{Y}=28655 \mathrm{X}-821$ & 0.9994 & $0.184-3.761$ & 0.055 & 0.166 \\
\hline Imp-5 & $\mathrm{Y}=66776 \mathrm{X}-3657$ & 0.9994 & $0.081-12.158$ & 0.027 & 0.081 \\
\hline ADB & $\mathrm{Y}=52406 \mathrm{X}-4155$ & 0.9982 & $0.099-7.615$ & 0.033 & 0.099 \\
\hline OSM & $\mathrm{Y}=46372 \mathrm{X}-3467$ & 0.9994 & $0.102-61.248$ & 0.027 & 0.081 \\
\hline Imp-6 & $\mathrm{Y}=32717 \mathrm{X}-2501$ & 0.9992 & $0.167-17.390$ & 0.055 & 0.167 \\
\hline Imp-7 & $\mathrm{Y}=38101 \mathrm{X}+461$ & 0.9997 & $0.192-3.713$ & 0.063 & 0.190 \\
\hline Imp-8 & $\mathrm{Y}=24156 \mathrm{X}+523$ & 0.9993 & $0.188-3.840$ & 0.042 & 0.126 \\
\hline Imp-9 & $\mathrm{Y}=38012 \mathrm{X}-1105$ & 0.9996 & $0.104-12.310$ & 0.061 & 0.184 \\
\hline \multicolumn{7}{|l|}{$* \mathrm{Y}$ is the peak area and X is the concentration injected } & \\
\hline
\end{tabular}

\section{Precision and Accuracy}

Method precision $(n=6)$ was performed on $\mathrm{ADB} / \mathrm{OSM}$ fixed dose form of tablets are spiked with all known related substances of both drug substances at proposed level were analysed and found \% RSD between 0-2.2\% range (acceptance limit \% RSD <5). Ruggedness $(n=6$, intermediate precision $)$ was evaluated by different analysis on different day on different instrument and column as per the methodology and found \% RSD between 0.2-1.7 range. Precision and ruggedness shows that the method has repeatability and reproducibility for all related substances in ADB and OSM substances in their tablets dosage forms and results were tabulated in Table-6. The accuracy was assessed by preparing triplicate $(n=3)$ sample solutions spiked with all known related substances of both drug substances from LOQ level to $150 \%$ of corresponding proposed level at four different levels at LOQ, 50\%, $100 \%$ and $150 \%$ level and the same were analyzed as per methodology. The experimental results revealed that $96.2 \%-105.7 \%$ recoveries were obtained for all the investigated related compounds. Therefore, based on the recovery data (Table-7) the estimation of related compounds that are prescribed in this report has been demonstrated to be accurate for intended purpose and is adequate for routine analysis.

Table-6: Results of Method Precision and Intermediate precision (Ruggedness) data

\begin{tabular}{|c|c|c|c|c|c|c|c|c|c|}
\hline \multirow[t]{2}{*}{ Analytes } & \multicolumn{4}{|c|}{ Method Precision $(M)(n=6)$} & \multicolumn{4}{|c|}{ Ruggedness (R) $(n=6)$} & \multirow{2}{*}{$\begin{array}{ll}\text { Overall } & \\
\% \text { RSD } & (M+R) \\
\end{array}$} \\
\hline & $N$ & $\mathbf{T}$ & $\begin{array}{l}\text { Mean } \\
\% \text { w/w }\end{array}$ & $\%$ RSD & $N$ & $\mathbf{T}$ & $\begin{array}{l}\text { Mean } \\
\% \text { w/w }\end{array}$ & $\%$ RSD & \\
\hline Imp-1 & 7869 & 1.1 & 1.292 & 2.2 & 8246 & 1.0 & 1.351 & 0.4 & 1.6 \\
\hline Imp-2 & 5426 & 1.1 & 1.081 & 0.9 & 6616 & 1.1 & 1.032 & 0.5 & 1.2 \\
\hline Imp-3 & 11752 & 1.1 & 1.240 & 0.6 & 13701 & 1.0 & 1.196 & 0.7 & 0.8 \\
\hline Imp-5 & 11628 & 1.0 & 0.511 & 0.6 & 11071 & 1.0 & 0.522 & 0.2 & 0.5 \\
\hline ADB & 11179 & 1.5 & 0.203 & 1.0 & 13015 & 1.4 & 0.200 & 1.0 & 1.0 \\
\hline OSM & 105796 & 0.9 & 0.191 & 0 & 109992 & 1.0 & 0.187 & 0.5 & 0.3 \\
\hline Imp-6 & 222807 & 1.0 & 0.663 & 0.6 & 204245 & 1.0 & 0.756 & 0.3 & 0.7 \\
\hline Imp-7 & 277561 & 1.1 & 1.039 & 1.8 & 301296 & 1.1 & 0.982 & 1.3 & 1.4 \\
\hline Imp-8 & 482313 & 1.2 & 0.984 & 1.3 & 420896 & 1.0 & 0.992 & 1.7 & 1.5 \\
\hline Imp-9 & 935921 & 1.0 & 0.508 & 1.1 & 925413 & 1.0 & 0.506 & 0.9 & 1.0 \\
\hline
\end{tabular}


Kondra Srinivasu et al; Saudi J Med Pharm Sci, Oct 2019; 5(10): 871-884

Table-7: Results of accuracy data for related substances of both ADB and OSM from LOQ to $150 \%$ level

\begin{tabular}{|c|c|c|c|c|c|c|c|c|}
\hline \multirow[t]{3}{*}{ Analytes } & \multicolumn{5}{|c|}{ Mean \% recovery $(n=3)$} & & \multirow{2}{*}{\multicolumn{2}{|c|}{$\begin{array}{l}\text { Over all statistical } \\
\text { parameters for } 50 \% \text { - } \\
150 \% \text { levels }\end{array}$}} \\
\hline & \multicolumn{2}{|l|}{ LOQ } & \multirow{2}{*}{$\begin{array}{l}\mathbf{5 0 \%} \\
\% \\
\text { Recovery } \\
\end{array}$} & \multirow{2}{*}{$\begin{array}{l}100 \% \\
\% \\
\text { Recovery } \\
\end{array}$} & \multirow{2}{*}{$\begin{array}{l}150 \% \\
\% \\
\text { Recovery } \\
\end{array}$} & \multirow[b]{2}{*}{$\begin{array}{l}\text { Mean } \\
\text { \% Recovery }\end{array}$} & & \\
\hline & $\begin{array}{l}\% \\
\text { Recovery }\end{array}$ & $\begin{array}{l}\% \\
\text { RSD }\end{array}$ & & & & & $\begin{array}{l}\% \\
\text { RSD }\end{array}$ & $\begin{array}{l}\text { 95\% Confidence } \\
\text { Interval }( \pm)\end{array}$ \\
\hline Imp-1 & 96.2 & 1.3 & 104.5 & 103.4 & 103.4 & 103.8 & 0.6 & 1.4 \\
\hline Imp-2 & 99.1 & 2.6 & 103.3 & 101.6 & 102.9 & 102.6 & 0.9 & 0.8 \\
\hline Imp-3 & 98.3 & 3.5 & 94.8 & 96.4 & 96.2 & 95.8 & 1.0 & 0.7 \\
\hline Imp-4 & 101.2 & 2.2 & 97.9 & 99.2 & 98.9 & 98.7 & 0.7 & 1.1 \\
\hline Imp-5 & 104.6 & 1.1 & 101.2 & 100.5 & 100.5 & 100.7 & 0.5 & 0.4 \\
\hline Imp-6 & 105.7 & 0.9 & 101.9 & 101.5 & 101.1 & 101.5 & 0.4 & 0.3 \\
\hline Imp-7 & 98.9 & 2.9 & 99.4 & 101.1 & 100.4 & 100.3 & 0.9 & 0.6 \\
\hline Imp-8 & 102.4 & 1.8 & 98.1 & 99.3 & 99.2 & 98.8 & 0.7 & 1.0 \\
\hline Imp-9 & 101.8 & 3.1 & 99.4 & 102.1 & 100.6 & 100.7 & 1.3 & 0.8 \\
\hline
\end{tabular}

\section{Robustness}

In order to demonstrate the strength of the method, the finalized chromatographic method parameters were deliberately altered to check robustness study. The operating parameters of the method were deliberately changed $\pm 10 \%$, in flow rate, $\pm 5^{\circ} \mathrm{C}$ column temperature, \pm 0.2 units in $\mathrm{pH}$ of the buffer, $\pm 1 \%$ in organic composition in mobile phase ( $\pm 1 \%$ absolute in Gradient composition) and $\pm 5 \mathrm{~nm}$ in detector wavelength were studied on the sample spiked with all known impurities and observed deliberate changes effect on all system suitability parameters like resolution, tailing factor and theoretical plates among the impurities. It can be found that there is no significant change and indicates the robustness of the method. Hence, the method was found to be robust across different variations studied for the experiment.

\section{Solution Stability}

The solution stability of standard solution and spiked sample of ADB/OSM with known related substances were determined by injecting the solutions immediately after preparation and at different regular time intervals by keeping the solution at room temperature $\left(25^{\circ} \mathrm{C}\right)$ and refrigerator $\left(6{ }^{\circ} \mathrm{C}\right)$. Standard solution was stable up to 60 hours at both room temperature $\left(25^{\circ} \mathrm{C}\right)$ and refrigerator $\left(6{ }^{\circ} \mathrm{C}\right)$. There is considerable change observed in the responses of impurities in sample solution after 5 hours at room temperature $\left(25^{\circ} \mathrm{C}\right)$ but in-case of refrigerator condition $\left(6{ }^{\circ} \mathrm{C}\right)$ no significant change observed in the $\%$ of impurities and no additional peaks observed in sample solution after 6 hours.

\section{CONCLUSIONS}

In this paper, a novel development technique for impurity profiling of $\mathrm{ADB} / \mathrm{OSM}$ in their fixed dose combination tablets by HPLC with online coupling of QDa with PDA detector was proposed and successfully validated. The significant advantage of this novel technique over conventional techniques is that identification and quantification can be evaluated simultaneously which enhances the analytical confidence in single run, monitors the co-elution, simplifies the identification and avoids repetition of analysis. Moreover, a systematic study was carried out on identification of major degradation product of OSM in $\mathrm{ADB} / \mathrm{OSM}$ product in stability evaluation samples by using HPLC-PDA-QDa mass detection and characterization by LC-MS/MS techniques. Validation experiments provided proof that developed the new stability indicating HPLC method is linear in the proposed working range as well as accurate, precise and robust. Due to these characteristics, the method has stability indicating properties being fit for its intended purpose. Hence, the information presented herein could be very useful for quality monitoring as well as impurity profiling of ADB/OSM fixed dose combination samples during manufacturing and stability studies.

\section{ACKNOWLEDGEMENT}

The authors gratefully acknowledge the management of APL Research Centre (A division of Aurobindo Pharma Limited) for allowing us to carry out the present work.

\section{REFERENCES}

1. Sweetmann, S. C. (1999). Martindal: the complete drug reference, 32 nd ed. The Pharmaceutical Press; London, 822.

2. Budavari, S. (1996). The Merck Index. 13th ed. NJ: Merck \& Co., Inc., Whitehouse Station, 491

3. Budavari, S. (1996). The Merck Index. 13th ed. NJ: Merck \& Co., Inc., Whitehouse Station, 6909.

4. Kim, S. W., Jun, S. S., Jo, Y. G., Koo, J. S., Lee, A. R., Son, J. W., \& Kim, J. T. (2009). Pharmaceutical Formulation containing angiotensin II receptor blocker. PCT Int. Appl. WO 134057 A2 20091105.

5. Horiuchi, M., Iwai, M., Sada, T., \& Mizuno, M. (2006) Composition comprising an angiotensinII receptor antagonist and a calcium channel blocker for prevention and treatment of arteriosclerosis and hypertension. U.S. Pat. Appl. Publ. US 20060009502 A1 20060112. 
6. Chen, X., Hu, P., Jiang, J., Liu, T., Zhong, W., Liu, H., \& Zhao, Q. (2012). Pharmacokinetic and pharmacodynamic profiles of a fixed-dose combination of olmesartan medoxomil and amlodipine in healthy Chinese males and females. Clinical drug investigation, 32(12), 783790.

7. Deeks, E. D. (2011). Olmesartan Medoxomil/Amlodipine/Hydrochlorothiazide. Dru gs, 71(2), 209-220.

8. Wankhede, S. B., Wadkar, S. B., Raka, K. C., \& Chitlange, S. S. (2009). Simultaneous estimation of amlodipine besilate and olmesartan medoxomil in pharmaceutical dosage form. Indian journal of pharmaceutical sciences, 71(5), 563-567.

9. Chauhan, K., Shah, J., \& Parmar, P. (2012). Development and validation of spectrophotometric methods for simultaneous estimation of Amlodipine Besylate and Olmesartan Medoxomil in combined dosage form. International Journal of Pharmacy and Pharmaceutical Sciences, 4, 337441.

10. Kardile, D. P., Kalyane, N. V., Thakkar, T. H., Patel, M. R., \& Moradiya, R. K. (2010). Simultaneous estimation of amlodipine besylate and olmesartan medoxomil drug formulations by HPLC and UV-spectrophotometric methods. $J$ Pharm Sci Res, 2(9), 599-614.

11. Jain, N., Jain, R., Banweer, J., \& Jain, D. K. (2010) Development and validation of a rapid RPHPLC method for the determination of Amlodipine Besylate and Olmesartan medoxomil in their combined tablet formulation From. International Journal of Current Pharmaceutical Research, 2(2), 40-43.

12. Patil, K. R., Rane, V. P., Sangshetti, J. N., Yeole, R. D., \& Shinde, D. B. (2010). Stability indicating LC method for the simultaneous determination of amlodipine and olmesartan in dosage form. Journal of chromatographic science, 48(7), 601-606.

13. Pournima, S. P., Harinath, N. M., \& Sachin, A. P. (2011). RP-HPLC method for simultaneous estimation of Amlodipine besylate and Olmesartan medoxomil from tablet From. International Journal of Pharmacy and Pharmaceutical Sciences, 3,146-149.

14. Mantena, B. P., Rao, S. V., Suryakala, D., Ramakrishna, K., \& Srikanth Reddy, R. (2016).
Rapid Analytical Technique for the Quantification of Specified and Unspecified Impurities Present in Amlodipine besylate and Olmesartan medoxomil Fixed Dose Combination Drug Product Using Ethylene-Bridged RP-UPLC Column. Analytical Chemistry Letters, 6(6), 795-819.

15. ICH, Q3B (R2). (2006). Impurities in New drug product, Conference on Harmonization, Geneva.

16. Guntupalli, S., Ray, U. K., Murali, N., Gupta, P. B., Kumar, V. J., Satheesh, D., \& Islam, A. (2014). Identification, isolation and characterization of process related impurities in ezetimibe. Journal of pharmaceutical and biomedical analysis, 88, 385-390.

17. Jagadabi, V., Nagendra Kumar, P. V., Mahesh, K., Pamidi, S., Ramaprasad, L. A., \& Nagaraju, D. (2018). A stability-indicating UPLC method for the determination of potential impurities and its mass by a new QDa mass detector in daclatasvir drug used to treat hepatitis C infection. Journal of chromatographic science, 57(1), 44-53.

18. Narayanam, M., Handa, T., Sharma, P., Jhajra, S., Muthe, P. K., Dappili, P. K., ... \& Singh, S. (2014). Critical practical aspects in the application of liquid chromatography-mass spectrometric studies for the characterization of impurities and degradation products. Journal of pharmaceutical and biomedical analysis, 87, 191-217.

19. ICH. Q2 (R1). (2000). Validation of analytical procedures: text and methodology, International Conference on Harmonization, Geneva.

20. ICH, Q1A (R2). (2005). Stability testing of new drug substances and products, International Conference on Harmonization, Geneva.

21. Murakami, T., Konno, H., Fukutsu, N., Onodera, M., Kawasaki, T., \& Kusu, F. (2008). Identification of a degradation product in stressed tablets of olmesartan medoxomil by the complementary use of HPLC hyphenated techniques. Journal of pharmaceutical and biomedical analysis, 47(3), 553-559.

22. United States pharmacopoeia. (2007). $30^{\text {th }}$ edition. U.S Pharmacopieal Convention Rockville, MD.

23. Gorenstein, M. V., Li, J. B., Van Antwerp, J., \& Chapman, D. (1994). Detecting coeluted impurities by spectral comparison. $L C G C, 12(10)$, 768-772. 